\title{
Low Plasma GABA Is a Trait-Like Marker for Bipolar Illness
}

Frederick Petty, Ph.D., M.D., Gerald L. Kramer, B.A., Mark Fulton, M.D., Frederick G. Moeller, M.D., and A. John Rush, M.D.

Plasma gamma-aminobutyric acid ( $p G A B A$ ) is an index of brain $G A B A$ activity and a peripheral marker of mood disorder. Previous research has indicated that $p G A B A$ is abnormally low in approximately $40 \%$ of patients symptomatic with primary unipolar depression. We have now measured $P G A B A$ in a series of patients with bipolar disorder. Blood samples for GABA determinations were collected soon after admission to hospital or clinic while patients were symptomatic. In both manic and depressed phase bipolar patients, mean levels of $p G A B A$ were significantly lower than in healthy control subjects. The distribution of $p G A B A$ in bipolar patients, whether manic or depressed, was similar to that in symptomatic unipolar depression, with $30 \%$ to $40 \%$ having $p G A B A$ levels lower than the control range. These data indicate that low pGABA is not specific to the depressed state, as it is also found in the manic phase of bipolar disorder. Low $p G A B A$ may represent a shared biologic correlate between bipolar and unipolar illness.

[Neuropsychopharmacology 9:125-132, 1993]

learned helplessness and olfactory bulbectomy animal models of depression, GABA agonists, including progabide and muscimol, have an antidepressant profile (Lloyd et al. 1983, 1987). Also, a wide range of chronically administered antidepressant and antimanic treatments, including tricyclic and atypical antidepressants, monoamine oxidase inhibitors, electroconvulsive shock, carbamazepine, valproic acid, and lithium, have been shown to "upregulate" GABA-B receptors in rat brain (Lloyd and Pichat 1985; Motohashi et al. 1989), although some laboratories report difficulty replicating this finding (Cross and Horton, 1989).

In vivo GABA tissue levels in human brain correlate inversely with severity of symptoms of depression (Honig et al. 1989). Post-mortem studies of suicides have generally revealed a low GABA state in these cases (Cross et al. 1988). Cerebrospinal fluid (CSF) levels of GABA in symptomatic depressed patients are significantly lower than controls in most (Gerner et al. 1984; Gold 1980; Gerner and Hare 1981; Kosa et al. 1982), but not all published studies. Patients with mania are also reported to have low CSF GABA, although the comparison with controls failed to reach statistical significance, perhaps due to small sample sizes (Gerner and Hare 1981). 
The precise origin of plasma GABA (pGABA) in humans is difficult to prove. However, GABA is a very CNS-specific compound. Ninety-nine percent of total body GABA and $95 \%$ of its synthesizing enzyme glutamic acid decarboxylase (GAD) is in brain and spinal cord (Zachmann et al. 1966). Concentrations of GABA in brain are high ( $4 \mathrm{mmol})$, and GABA is synthesized from glutamate $(100 \mathrm{mmol})$ at a rate of about 40 $\mathrm{mmol} / \mathrm{hr}$, therefore providing a theoretical brain turnover time of about 6 minutes. By contrast, except for oviduct, islets of Langerhans and pineal, peripheral tissue and organ GABA levels are in the micromolar range or lower (Erdo and Kiss, 1986). Furthermore, the activity of GAD in the periphery is only $1 \%$ to $15 \%$ of that in brain (Fogel, 1986).

Gamma-aminobutyric acid does not readily cross the blood-brain barrier (Krogsgaard-Larsen 1992; Loscher 1982). Even when pGABA levels are elevated by fulminant hepatic failure in humans (Record et al. 1976) or portocaval shunting in rats (Mans et al. 1992), brain GABA levels and GABA receptor binding are unaltered. There are no correlations between pGABA levels in hepatic failure and grade of encephalopathy (Singh et al. 1985) or performance on psychometric tests (Losher et al. 1991). Increased brain GABA "tone" in hepatic encephalopathy probably derives from increased brain benzodiazepine-like compound concentrations in most cases (Basile et al. 1991), with the origin of these benzodiazepines yet to be elucidated.

Gamma-aminobutyric acid transport from brain extracellular fluid (ECF) to CSF occurs by passive diffusion (Davson 1976). Uptake mechanisms for GABA from ECF by neurons and glia are extremely efficient, and concentrations of GABA in ECF are the lowest of any neurotransmitter yet measured (Drew et al. 1989). Concentrations of GABA in ECF and CSF are comparable (120 vs. $100 \mathrm{nmol}$ ).

Gamma-aminobutyric acid is actively transported from CSF to plasma (Snodgrass and Lorenzo 1973; Loscher 1982). Concentrations of GABA in plasma and CSF are remarkably similar (100 $\mathrm{nmol})$ in healthy humans (Uhlhaas et al. 1986), suggesting the absence of a gradient between these two compartments (Loscher and Schmidt 1984).

Cerebrospinal fluid GABA is of brain origin, and there is a high correlation between CSF and pGABA levels in rats (Bohlen et al. 1979; Ferkany et al. 1979), dogs (Loscher 1982), and normal humans (Uhlhaas et al. 1986) $(r=0.67,0.59$, and 0.51 respectively, $p<.01)$.

Pharmacologic manipulations that change brain levels of GABA also change pGABA levels in similar proportion (Loscher 1979; Ferkany et al. 1979; Bohlen et al. 1979). Of particular interest is the finding that pGABA increased after intracerebroventricular administration of an inhibitor of GABA transaminase (GABA-T) but not after intraperitoneal administration of the drug (Loscher 1979). Also, increase in pGABA is seen after the increase in brain GABA (Apud et al. 1981). Inhibition of GAD causes a decrease in pGABA (Ferkany et al. 1979). Furthermore, it may be that the small amounts of GABA found in peripheral tissue are not derived from glutamate through GAD but rather from putrescine (Caron et al. 1988).

Metabolism of pGABA is by GABA-T in the liver. Activity of GABA-T in liver is almost as high as in brain. Hepatic clearance of pGABA is very rapid such that within 4 minutes, $90 \%$ of an exogenous load has been cleared (Minuk 1986). Platelets also have significant GABA-T activity and an active uptake for GABA, but their role in peripheral GABA homeostasis is probably minor (Oset-Gasque et al. 1986).

Based on pool size, transport between pools, and GABA concentrations, a peripheral source for $\mathrm{pGABA}$ need not be invoked but cannot be entirely ruled out (Figure 1). The most parsimonious explanation for the known data is that pGABA is probably derived largely from brain and may possibly provide a useful peripheral marker of brain GABA activity (Rundfeldt and Losher 1992). However, it is important to note that the precise origin of pGABA is not critical to its being a biologic marker. Even peripheral markers of psychiatric illness can be theoretically important and clinically useful.

Plasma GABA is significantly low in patients symptomatic with primary unipolar depression, with about $40 \%$ of patients having pGABA levels lower than $95 \%$ of controls (Petty et al. 1992). In earlier studies, we reported pGABA levels to be high in patients with mania and similar to control in bipolar depressed phase patients (Petty and Sherman 1982). Plasma GABA is also low in recently detoxified alcoholics (Coffman and Petty 1984). However, this work used a gas chromatographic assay for pGABA, which measures total GABA (free + conjugated). Berrettini et al. (1986) reported that drug-free euthymic bipolar patients had low pGABA when measured with a high-performance liquid chromatography (HPLC) assay specific for free pGABA.

In the present study, we have measured free plasma levels of GABA using HPLC in a series of bipolar inpatients and outpatients who were symptomatic either in the manic or depressed phase at the time of study.

\section{MATERIALS AND METHODS}

\section{Subjects}

Subjects were recruited from consecutive admissions to the inpatient wards and outpatient clinic of the Psychiatry Service at the Dallas VA Medical Center. All provided written informed consent. Diagnoses were determined according to DSM-III-R criteria using the Structured Clinical Interview for DSM-III-R (SCID; Spit- 


\section{GABA Pools, Concentrations, and Transport}

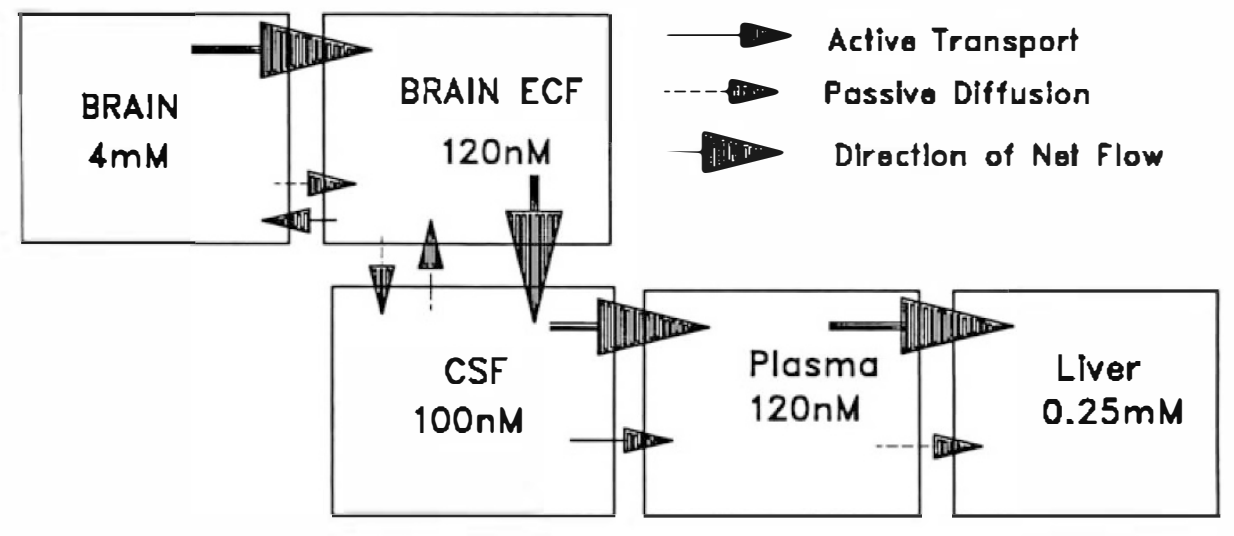

Figure 1. GABA Transport System. zer et al. 1990). Additionally, for inclusion in the study, patients were also required to meet criteria of Feighner et al. (1972) for depression and mania, which required a length of illness of at least 1 month for depression and at least 1 week for mania. Exclusion criteria were unstable medical condition, history of epilepsy, history of alcoholism, use of medication known to affect GABA, and other current Axis I disorders, such as substance abuse. Severity of depression was assessed with the 17-Item Hamilton (1960) Depression Rating Scale (HDRS). Two bipolar, depressed phase, patients were excluded from analysis because their HDRS scores were less than 12. Bipolar disorder, mixed, was classified as bipolar manic.

Control volunteers were screened with a SCID and the SCID-II (Spitzer et al. 1989) and were negative for history of Axis I or II diagnosis. Family history from the subject of psychiatric or neurological illness in firstdegree relatives was also negative. None had any medical condition requiring ongoing treatment, and all were medication free for 1 month prior to sampling.

Within 3 days of intake, blood samples for pGABA determination were obtained between 0700 and 0900 hours by venipuncture, centrifuged promptly, and frozen until assay at $-70^{\circ} \mathrm{C}$. Assays were performed within 6 months of sample collection.

\section{Assay}

Plasma GABA was determined, with minor modifications, by the procedure of Hare and Manyam (1980). Samples were deproteinated with sulfosalicylic acid, and gamma-vinyl GABA was used as an internal standard. Chromatography was achieved with an ionexchange column, a mobile phase of lithium citrate buffer ( $\mathrm{pH}$ 4.6), and detection with fluorometry after postcolumn derivatization with orthophthalaldehyde.
The response is linear from 20 to $500 \mathrm{pmol} / \mathrm{ml}$, with an intraassay coefficient of variation of $3.9 \%$ and an interassay CV of $6.4 \%$.

\section{Statistical Analysis}

Because of significant heterogeneity of variance in pGABA levels, group differences were assessed by means of the Kruskal-Wallis analysis of variance. Pairwise differences were then assessed by means of Dunn's test. Plasma GABA levels were categorized on the basis of being either less than or equal to a value of 100 $\mathrm{pmol} / \mathrm{ml}$ or strictly great than $100 \mathrm{pmol} / \mathrm{ml}$. This category represents a natural cutoff with $94 \%$ of healthy controls above this value. Chi-square analysis was used to assess for differences between groups on this categorical variable, and pairwise differences were assessed taking into account corrections for multiple comparisons. All multiple comparison procedures were made following recommendations in Woolson (1987).

\section{RESULTS}

\section{Group Differences}

Demographic and clinical variables for the sample are presented in Table 1. Controls had a significantly lower mean score on the HDRS, but were otherwise comparable to patients.

Plasma GABA levels for the three study groups are shown in Figure 2. Nonparametric analysis of variance showed that the distribution of PGABA in the two patient groups was markedly different from control (Kruskal-Wallis test statistic $=15.00, p=.001$ ). Group comparisons showed that controls differed significantly from both the bipolar depressed phase $(p=.0004)$ and the bipolar manic phase $(p=.05)$ groups. 
Table 1. Demographic and Clinical Variables

\begin{tabular}{lcccc}
\hline & $\begin{array}{c}\text { Normal } \\
\text { Controls } \\
\boldsymbol{n}=\mathbf{5 0}\end{array}$ & $\begin{array}{c}\text { Bipolar } \\
\text { Depressed } \\
\boldsymbol{n}=\mathbf{3 3}\end{array}$ & $\begin{array}{c}\text { Bipolar } \\
\text { Manic } \\
\boldsymbol{n}=\mathbf{2 4}\end{array}$ & $\boldsymbol{p}$ \\
\hline pGABA (pmol/ml) & $126.4 \pm 16.3$ & $112.1 \pm 33.0$ & $114.0 \pm 25.9$ & 0.001 \\
Age (yr) & $40.0 \pm 9.9$ & $41.2 \pm 9.4$ & $46.1 \pm 13.1$ & 0.07 \\
Height (m) & $1.79 \pm 0.06$ & $1.77 \pm 0.09$ & $1.79 \pm 0.06$ & 0.33 \\
Weight (kg) & $81.0 \pm 15.6$ & $84.1 \pm 14.5$ & $80.8 \pm 15.6$ & 0.48 \\
HDRS & $0.6 \pm 1.2$ & $26.2 \pm 6.2$ & $7.8 \pm 8.3$ & $<0.001$ \\
\hline
\end{tabular}

Data are presented as mean \pm standard deviation.

\section{Categorical Grouping}

To utilize pGABA as a categorical test, we compared the groups on the basis of low pGABA, where low pGABA is defined as being less than or equal to 100 $\mathrm{pmol} / \mathrm{ml}$. These group differences are shown in Figure 3. Although only $6 \%$ of the control group had pGABA levels below $100 \mathrm{pmol} / \mathrm{ml}, 42 \%$ of the bipolar, depressed-phase and $29 \%$ of the manic-phase patients had levels below $100 \mathrm{pmol} / \mathrm{ml}$. The difference between these proportions is highly significant $\left(\chi^{2}=15.97\right.$; $p<.001$ ) by chi-square analysis. Pairwise group comparison showed that the proportion of controls with low pGABA differed significantly from the bipolar depressed group (estimated difference in proportion $=$ $.36,95 \%$ confidence interval .14 to .59), but not from the bipolar manic group (estimated difference in propor- tion $=.23,95 \%$ confidence interval -.01 to .47$)$. The two patient groups did not differ on levels of pGABA (estimated difference in proportions $=.13,95 \%$ confidence interval -.18 to .44 ).

\section{Medication Effects}

Of the 57 patients, 34 were medication free at the time of sampling, and 23 were either on a single psychotropic medication ( $n=6)$ (lithium, antidepressants) or were on two or more drugs including nonpsychotropic medications $(n=17)$. In the entire patient group, the medication-free patients did not differ from the medicated patients in pGABA levels (Table 2). However, fur. ther analysis revealed a significant effect in the bipolar depressed group but not the bipolar manic group.
Figure 2. Plasma levels of GABA (in pmol/ml) plotted separately for controls and patient groups. Raw data are overlaid with box plots demarcating the median, upper and lower quartiles, and upper and lower hinges. There are two outliers in the bipolar depressed group.

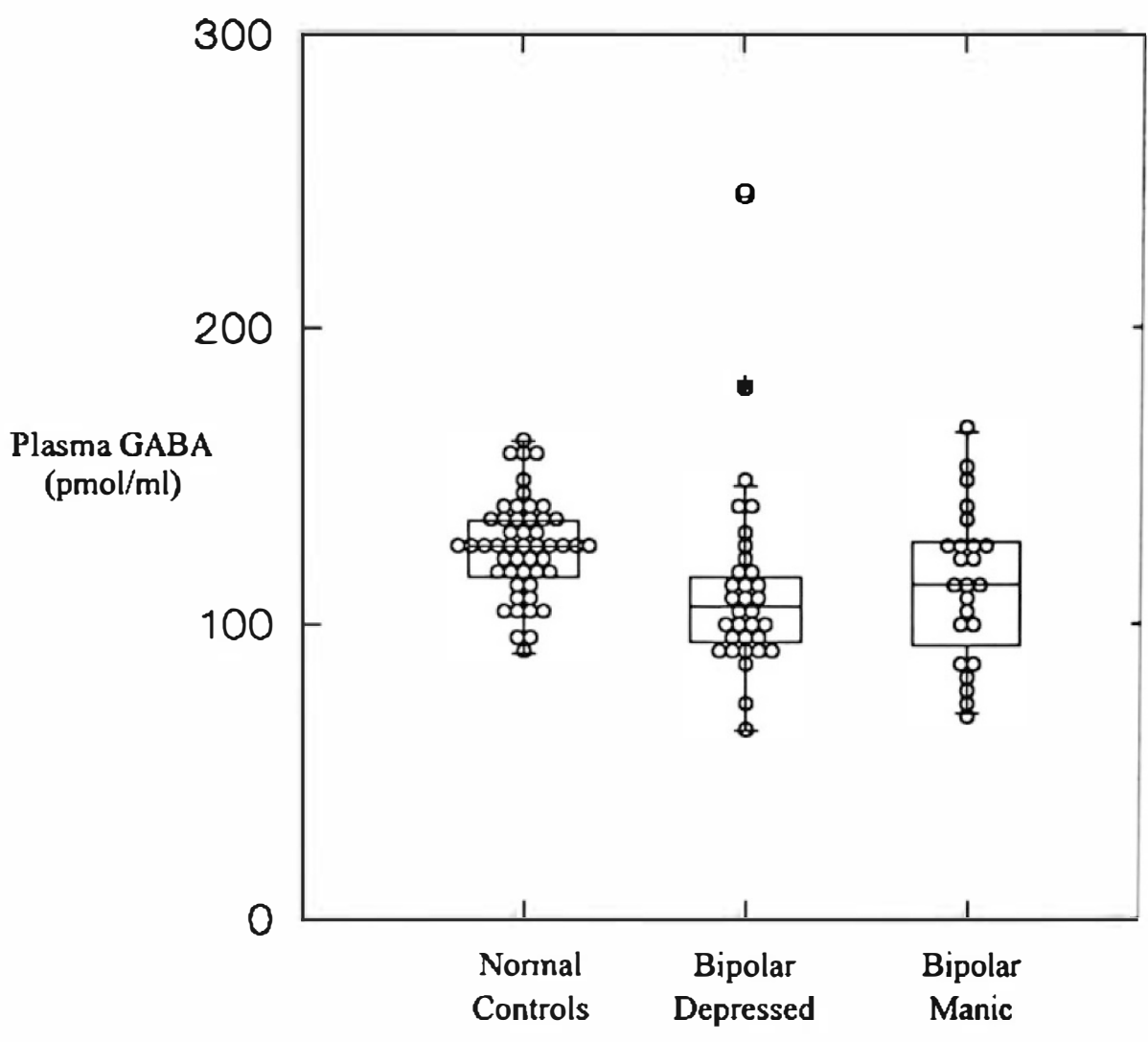




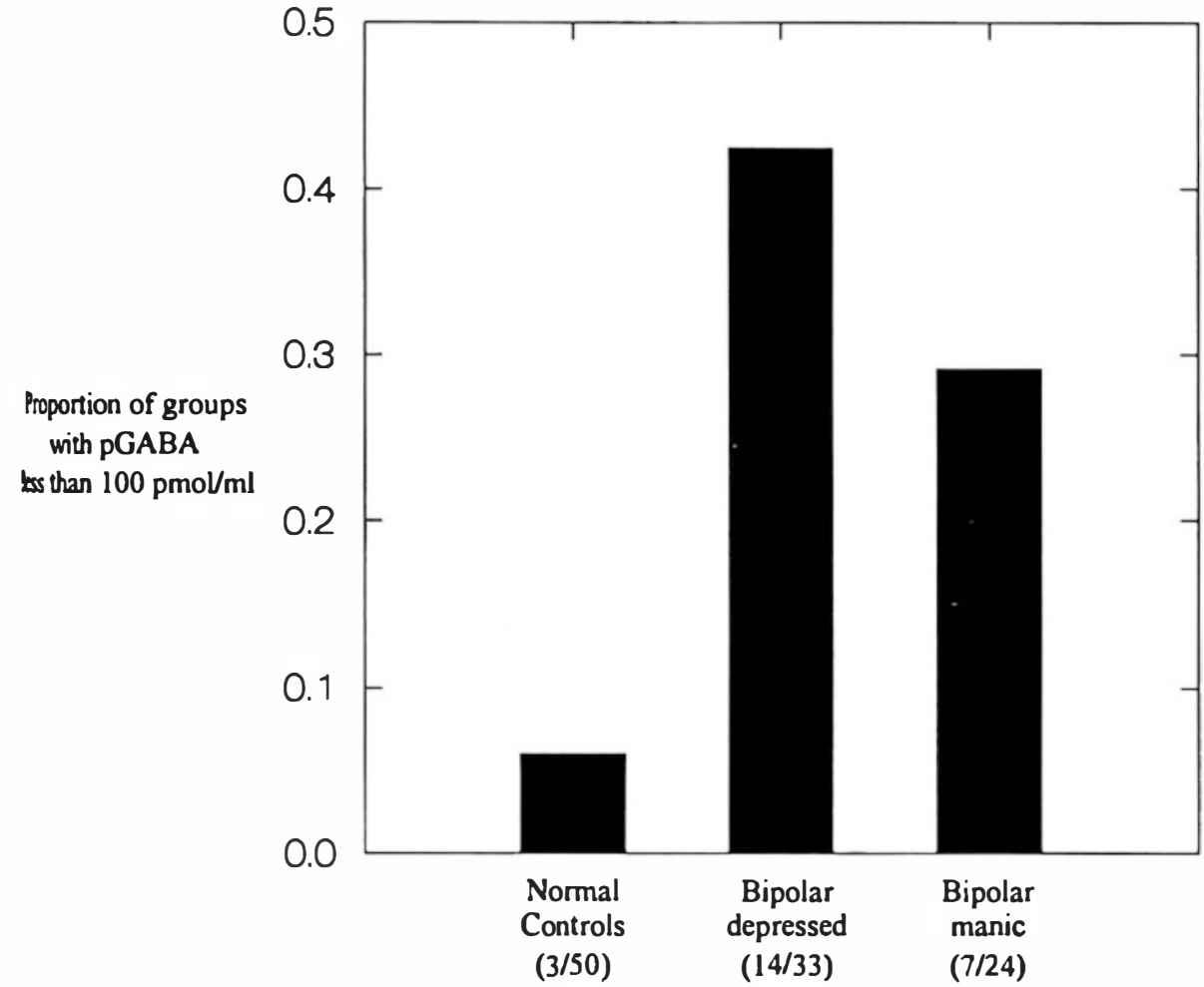

Figure 3. Proportion of each study group with low $\mathrm{PGABA}$ (defined as less than $100 \mathrm{pmol} /$ $\mathrm{ml})$.
Medication-free bipolar depressed patients had lower PGABA.

\section{DISCUSSION}

Over one third of the patients with bipolar mood disorder have low pGABA, whether in the manic or depressed phase of the illness. Therefore, low pGABA is not specific to the state of depression because it is also found in the manic phase. Further evidence for the notion that low pGABA may be a trait marker in bipolar illness was provided by the finding of Berrettini et al. (1986) of low pGABA in drug-free euthymic bipolars.

Criteria for a biologic marker of a psychiatric illness have been formulated (for review Gershon and Goldin 1986; Nurnberger 1992). These include: (1) presence of the marker in patients but not controls; (2) state independence; (3) heritability; and (4) segregation with ill- ness in pedigrees. Evidence available to date suggests that low pGABA distinguishes about one third of bipolar patients and is state independent. However, at this time there is some evidence of heritability because monozygotic twins have similar pGABA levels $(r=$ $0.73, p<.01$ ) (Berrettini et al. 1982), but no information on pedigree segregation. Additional research is needed to clarify these issues.

Mean pGABA levels and the proportion of subjects with markedly low pGABA are comparable for symptomatic bipolar and symptomatic unipolar patients (Petty et al. 1992). This demonstrates that low pGABA as a biologic marker is not specific to either unipolar or bipolar mood disorder but is seen in both in approximately the same proportion. Although the clinical delineation of mood disorders for schizophrenic syndromes was made approximately 80 years ago, the further subdivision of mood disorders into unipolar and bipolar types was not widely accepted until about 20

Table 2. Effect of Medications on Plasma GABA

\begin{tabular}{|c|c|c|c|c|c|c|}
\hline & \multicolumn{2}{|c|}{ Bipolar Depressed } & \multicolumn{2}{|c|}{ Bipolar Manic } & \multicolumn{2}{|c|}{ Total } \\
\hline & $\begin{array}{c}\text { On Meds } \\
n=15\end{array}$ & $\begin{array}{c}\text { No Meds } \\
n=18\end{array}$ & $\begin{array}{c}\text { On Meds } \\
n=28\end{array}$ & $\begin{array}{c}\text { No Meds } \\
n=16\end{array}$ & $\begin{array}{c}\text { On Meds } \\
n=23\end{array}$ & $\begin{array}{c}\text { No Meds } \\
n=34\end{array}$ \\
\hline $\begin{array}{l}\text { GABA } \\
(\mathrm{pmol} / \mathrm{ml})\end{array}$ & $124 \pm 43^{\star}$ & $102 \pm 17$ & $110 \pm 31$ & $116 \pm 24$ & $119 \pm 39$ & $108 \pm 21$ \\
\hline
\end{tabular}

Data presented as mean \pm standard deviation.

${ }^{*} p<.05$ versus bipolar depressed no meds group. 
years ago, suggestion that from a clinical perspective, bipolar and unipolar (particularly recurrent unipolars) disorders may well be more alike than dissimilar. Other similarities exist. Unipolar depression is found in the families of bipolar patients as often as bipolar disorder (for a review see Rush et al. 1991). The dexamethasone suppression test is abnormal in both unipolar depression and in bipolar, depressed phase, disorder. Therefore, finding low pGABA in a subset of mood-disordered patients, whether depressed or manic, unipolar or bipolar, is neither peculiar nor particularly surprising and is precisely what one might predict for a genetic trait marker.

Our early studies (Petty and Sherman 1982) which found elevated pGABA in manics deserve comment. Gamma-aminobutyric acid in plasma is mostly conjugated to other amino acids to form dipeptides such as homocarnosine with only about $30 \%$ present as free pGABA (Uhlhaas and Olek 1985). The gas chromatographic (GC) technique that we previously used (Petty and Sherman 1982) involves sample derivatization with strong acids at high temperatures sufficient to hydrolyze peptide bonds. Therefore, levels of pGABA measured by GC are about five times higher than those measured by HPLC. High-performance liquid chromatography does not involve derivatization before chromatographic separation, and protein precipitation is done with mild conditions that do not lead to hydrolysis. Therefore, the different results obtained by GC versus HPLC are not contradictory, but in fact suggest that conjugated GABA (and therefore total GABA) is elevated in mania, while free GABA is low.

The specificity of low pGABA for mood disorders appears to be rather robust. Schizophrenia, panic disorder, bulimia, anorexia, and generalized anxiety disorder are not associated with abnormal pGABA (Petty et al. 1982, 1988), whereas $33 \%$ of nondepressed alcoholics have low pGABA (Petty et al. 1992). However, there may be a close relationship between mood disorders and alcoholism (Coryell et al. 1992).

There were several limitations to the present study. First, 23 of the 57 patients studied were on some type of medication. However, as seen in the bipolar, depressed-phase group, the patients off medication had significantly lower pGABA, and the effect of medication was not to lower pGABA levels. If anything, a more robust group difference would have resulted if only medication-free patients were included. Medication in the bipolar, depressed-phase group was more likely associated with normal plasma GABA. Whether this was due to chance or was a specific medication effect cannot be determined.

Second, there was no systematic attempt to subclassify patients in the manic phase who had mixed symptoms. It is possible that the manic patients with lower pGABA levels were experiencing dysphoric ma- nia, were about to enter a depressed phase, or had just recently left the depressed phase. Future research should clarify these issues.

The present data do not clarify whether treatment response in the bipolar, depressed phase correlates with pGABA, a topic for future research. Furthermore, metabolic pathways of GABA synthesis and metabolism conjugation are relatively simple, and future studies should examine whether depressed and bipolar patients with low pGABA also share a possibly inherited defecl in the relevant enzymes.

\section{ACKNOWLEDGMENTS}

This work was supported by the Department of Veterans Affairs, NIMH Research Grant MH37899; NIAAA Research Grant AA07234, MHCRC Center Grant MH41115, and the John Schemmerhorn Fund. We thank Glynda Mekonen for excellent secretarial support in preparing the manuscript. Melissa Waddill, B.A. and Jack Bittle for technical assistance: and Kenneth Z. Altshuler, M.D., Stanton Sharpe Professor and Chairman, for administrative support.

\section{REFERENCES}

Apud JA, Racagnia G, Iuliano E, Cocchi D, Casanueva F Muller EE (1981): Role of central nervous system-derived or circulating $\gamma$-aminobutyric acid in prolactin secretion in the rat. Endocrinology 108:1505-1510

Basile AS, Hughes RD, Harrison PM, Murata Y, Pannel L Jones A, Williams, R, Skolnick P (1991): Elevated brain concentrations of 1,4-benzodiazepines in fulminanthe patic failure. N Engl J Med 325:473-478

Berrettini WH, Nurnberger JI, Hare T, Gershon ES, Post RM (1982): Plasma and CSF GABA in affective illness. $\mathrm{Br}$ ) Psychiatry 141:483-487

Berrettini WH, Nurnberger JI, Hare TA, Simmons-Alling $S$ Gershon ES (1986): CSF GABA in euthymic manic depressive patients and controls. Biol Psychiatry 21: 842-844

Berrettini WH, Nurnberger JI, Scheinin M, Seppala T, Linnoila M, Narrow W, Simmons-Alling S, Gershon ES (1985): Cerebrospinal fluid and plasma monoamines and their metabolites in euthymic bipolar patients. Biol Ps: chiatry 20:257-269

Bohlen P, Huot S, Palfreyman MG (1979): The relationship between GABA concentrations in brain and cerebrosp: nal fluid. Brain Res 167:297-305

Caron PC, Cote LJ, Kremzner LT (1988): Putrescine, a source of $y$-aminobutyric acid in the adrenal gland of the rat Biochem J 251:559-562

Coryell W, Winokur G, Keller M, Scheftner W, Endicott] (1992): Alcoholism and primary major depression: A family study approach to co-existing disorders. J Affect Dis ord 24:93-99

Cross JA, Cheetham SC, Crompton MR, Katona CLE, Hor ton RW (1988): Brain GABA-B binding sites in depressed suicide victims. Psychiatry Res 26:119-129

Cross JA, Horton RW (1987): Are increases in GABA-B recef 
tors consistent findings following chronic antidepressant administration? Eur J Pharmacol 141:159-162

Davson H (1976): The blood-brain barrier. J Physiol (Lond) 255:1-28

Drew KL, O'Connor WT, Kehr J, Ungerstedt U (1989): Characterization of gamma-aminobutyric acid and dopamine overflow following acute implantation of a microdialysis probe. Life Sci 45:1301-1317

Emrich HM, Zerssen DV, Kissling W, Moller H-J, Windorfer A (1980): Effect of sodium valproate on mania. Arch Psychiatr Nervenkr 229:1-16

Erdo SL, Kiss B (1986): Presence of GABA, glutamate decarboxylase, and GABA transaminase in peripheral tissues: a collection of quantitative data. In Erdo SL, Bowery NG (eds), GABAergic Mechanisms in the Mammalian Periphery. New York, Raven Press, pp 5-17

Feighner JP, Robins E, Guze SB, Woodruff RA, Winokur G, Munoz R (1972): Diagnostic criteria for use in psychiatric research. Arch Gen Psychiatry 26:57-63

Ferkany JW, Butler IJ, Enna SJ (1979): Effect of drugs on rat brain, cerebrospinal fluid and blood GABA content. J Neurochem 33:29-33

Fogel WA (1986): GABA and polyamine metabolism in peripheral tissues. In Erdo SL, Bowery NG (eds), GABAergic Mechanisms in the Mammalian Periphery. New York, Raven Press, pp 35-56

Gerner RH, Fairbanks L, Anderson GM, Young JG, Scheinin M, Linnoila M, Hare TA, Shaywitz BA, Cohen DJ (1984): CSF neurochemistry in depressed, manic, and schizophrenic patients compared with that of normal controls. Am J Psychiatry 141:1533-1540

Gerner RH, Hare TA (1981): CSF GABA in normal subjects and patients with depression, schizophrenia, mania, and anorexia nervosa. Am J Psychiatry 138:1098-1101

Gershon ES, Goldin LR(1986). Clinical methods in psychiatric genetics. Acta Psychiatr Scand 74:113-118

Gold BI, Bowers MB, Roth RH, Sweeney DW (1980): GABA levels in CSF of patients with psychiatric disorders. Am J Psychiatry 137:362-364

Hamilton M (1960): A rating scale for depression. J Neurol Neurosurg Psychiatry 23:56-62

Hare TA, Manyam NVB (1980): Rapid and sensitive ionexchange fluorometric measurement of $\gamma$-aminobutyric acids in physiological fluids. Anal Biochem 101:349-355

Honig A, Bartlett JR, Bouras N, Bridges PK (1989): Amino acid level in depression: A preliminary investigation. J Psychiatry Res 22:159-164

Kasa K, Otsuki S, Yamamoto M, Sato M, Kuroda H, Ogawa $\mathrm{N}$ (1982): Cerebrospinal fluid $\gamma$-aminobutyric acid and homovanillic acid in depressive disorders. Biol Psychiatry 17:877-883

Krogsgaard-Larsen P (1992): GABA and glutamate receptors as therapeutic targets in neurodegenerative disorders. Pharmacol Toxicol 70:95-104

Lloyd KG, Morselli PL, Depoortere H, Fournier V, Zivkovic B, Scatton B, Broekkamp C, Worms P, Bartholini G (1983): The potential use of GABA agonists in psychiatric disorders: Evidence from studies with progabide in animal models and clinical trials. Pharmacol Biochem Behav 18:957-966
Lloyd KG, Pichat P (1985): Decrease in GABA-B binding in the frontal cortex of olfactory bulbectomized rats. Br J Pharmacol 87:36P (Abstract)

Lloyd KG, Zivkovic B, Sanger D, Depoortere H, Bartholini $G$ (1987): Fengabine, a novel antidepressant GABAergic agent. I. Activity in models for antidepressant drugs and psychopharmacological profile. J Pharmacol Exp Ther 241:245-250

Lloyd KG, Zivkovic B, Scatton B, Morselli PL, Bartholini G (1989): the GABAergic hypothesis of depression. Prog Neuropsychopharmacol Biol Psychiatry 13:341-351

Loscher W (1979): GABA in plasma and cerebrospinal fluid of different species. Effects of $\gamma$-acetylenic GABA, $\gamma$-vinyl GABA and sodium valproate. J Neurochem 32:1587-1591

Loscher W (1982): Relationship between GABA concentrations in cerebrospinal fluid and seizure excitability. J Neurochem 38:293-295

Loscher W, Frey H-H(1982): Transport of GABA at the bloodCSF interface. J Neurochem 38:1072-1079

Loscher W, Kretz F-J, Karavias T, Dillinger U (1991): Marked increases of plasma gamma-aminobutyric acid concentrations in cirrhotic patients with portocaval shunts are not associated with alterations of cerebral functions. Digestion 49:212-220

Loscher W, Schmidt D (1984): Monitoring of $\gamma$-aminobutyric acid in human cerebrospinal fluid: Downward revision of previous control values. Ther Drug Monit 6:227-231

Mans AM, Kukulka KM, McAvoy KJ, Rokosz NC (1992): Regional distribution and kinetics of three sites on the GABAA receptor: Lack of effect of portocaval shunting. J Cereb Blood Flow Metab 12:334-346

Minuk GY (1986): GABAergic mechanisms and their functional importance in the liver. In Erdo SL, Bowery NG (eds), GABAergic Mechanisms in the Mammalian Periphery. New York, Raven Press, pp 325-337

MotohashiN, Ikawa K, Kariya T (1989): GABAB receptors are up-regulated by chronic treatment with lithium or carbamazepine. GABA hypothesis of affective disorders? Eur J Pharmacol 166:95-99

Nurnberger JI Jr (1992): Should a biologic marker be sensitive and specific? [Review]. Acta Psychiatr Scand 86:1-4

Oset-Gasque MJ, Launay JM, Gonzalez MP (1986): GABAergic mechanisms in blood cells: Their possible role. In Erdo SL, Bowery NG (eds), GABAergic Mechanisms in the Mammalian Periphery. New York, Raven Press, pp 305-342

Petty F, Sherman AD (1982): Plasma GABA: A blood test for bipolar affective disorder trait? Res Commun Psychol Psychiatr Behav 7:431-440

Petty F, Coffman JA (1984): Plasma GABA: A possible indicator of altered GABA function in psychiatric illness. Neuropharmacology 23:849-850

Petty F, Fulton M, Trivedi M, Moeller FG, Rush AJ (1993): Alprazolam as an antidepressant. J Affect Dis (submitted)

Petty F, Kramer GL, Gullion CM, Rush AJ (1992): Low plasma gamma-aminobutyric acid levels in male patients with depression. Biol Psychiatry 32:354-363

Record CO (1976): Plasma and brain amino acids in fulminant hepatic failure and their relationships to hepatic encephalography. Eur J Clin Invest 6:387-394 
Rundfeldt C, Loscher W (1992): Development of tolerance to the anticonvulsant effect of vigabatrin in amygdalakindled rats. Eur J Pharmacol 213:351-366

Rush AJ, Cain JW, Raese J, Stewart RS, Waller DA, Debus JD (1991): Neurobiological bases for psychiatric disorders. In Rosenberg RN (ed), Comprehensive Neurology. New York, Raven Press, pp 555-603

Singh NK, Thapliyla A, Jain AK, Chansuria JPN, Gupta JP, Srivastava PK (1985): Alterations in plasma and CSF levels of GABA, 5-HT and amino acids in fulminant hepatic failure. Indian J Gastroenterol 4:253-255

Snodgrass R, Lorenzo AV (1973): Transport of GABA from the perfused ventricular system of the cat. J Neurochem 20:761-769

Spitzer RL, Williams JBW, Gibbon M, First MB (1989): Structured Clinical Interview for DSM-III-R.-Personality Dis- orders. Biometrics Research Department, New York State Psychiatric Institute, New York, NY

Spitzer RL, Williams JBW, Gibbon M, First MB (1990): Structured Clinical Interview for DSM-III-R. Washington, D.C., American Psychiatric Press

Uhlhaas VS, Lanage H, Wappenschmidt J, Olek K (1986): Free and conjugated CSF and plasma GABA in Huntington's chorea. Acta Neurol Scand 74:261-265

Uhlhaas VS, Olek K (1985): Konzentrationen von frier und gebundener 4-aminobuttersaure im menschlichen senum. J Clin Chem Clin Biochem 23:525-528

Woolson RF (1987): Statistical Methods for the Analysis of Biomedical Data. New York, J Wiley \& Sons

Zachmann M, Tocci P, Nyhan WL (1966): The occurrence of $\gamma$-aminobutyric acid in human tissues other than brain. J Biol Chem 241:1355-1358 